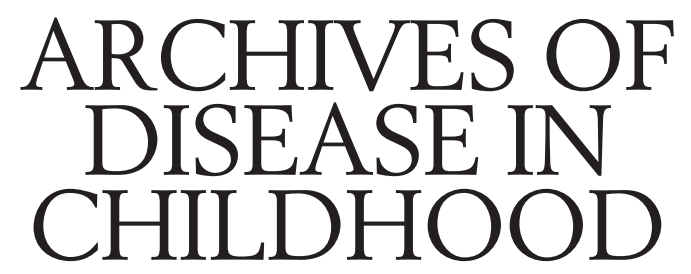

The Journal of the Royal College of Paediatrics and Child Health

\title{
Annotations
}

\section{Molecular basis of virulence}

Advances in molecular biology, cell biology, and several other areas of science have changed the way we understand the mechanisms in which microbial pathogens interact with their hosts. This trend is set to continue with the advent of microbial genome sequencing, in vivo gene expression analysis, and other related techniques. The availability of these techniques and advances in other areas such as protein expression and crystallography has allowed the understanding of host pathogen interaction at the molecular and even atomic level. However, despite these powerful approaches the basic concept advanced many years ago by Smith that pathogenicity or virulence is a multifactorial property that consists of five basic steps is still valid today. ${ }^{1}$ The molecular basis of virulence can still be considered under these five headings: (1) attachment to the host (via mucous membranes); (2) entry into the host (usually); (3) multiplication within the host; (4) Interference with host defence systems; (5) damage to the host.

These five stages are not mutually exclusive. The factors produced by pathogens that mediate these steps are termed the determinants of microbial pathogenicity. The molecular basis of these steps will be considered and specific examples will be given to demonstrate the basic principles. Finally it should be emphasised that expression of determinants of pathogenicity is usually regulated and systems exist for environmental sensing and quorum sensing to allow appropriate expression of virulence factors.

\section{(1) Attachment to the host}

Attachment of bacteria to host cells is mediated by adhesins, which have been identified for many bacterial species. ${ }^{2-5}$ Most adhesins are proteins which usually bind to carbohydrate receptors on the host cell surface. Perhaps the most studied adhesins are the fimbrial adhesins of Escherichia coli. These can be divided into two families. The K88, K99, CFA/I, and CFA/II adhesins mediate attachment to gut epithelium while type $1, \mathrm{P}$, and $\mathrm{S}$ fimbriae are associated with infections of the urinary tract. Fimbriae tend to be composed of a helical structure of major protein subunits which act as a support for the minor protein subunits. The minor protein subunits determine the receptor specificity for type $1, \mathrm{P}$, and $\mathrm{S}$ fimbriae whereas receptor specificity is determined by the major protein subunits in the attachment to gut epithelium. Fimbriae genes have been cloned and sequenced and the individual amino acids responsible for the interaction with the host cell receptors have in some cases been determined, for example lysine and arginine residues at positions 116 and 118 appear to be important for the Sfa minor subunit of $S$ fimbriae. ${ }^{6}$ Host cell receptors for attachment of bacteria have also been characterised at the molecular level, for example $\beta-D-G a l$ groups are the ligand for K88 fimbriae. It should be pointed out that interaction between a pathogen and host is not mediated by a single adhesin/receptor interaction. A good example of this fact is the interaction of the respiratory pathogen Streptococcus pneumoniae (the pneumococcus) with host cells. At least four types of receptor have been proposed for the pneumococcus and the interaction with these receptors depends on the phenotype of the organism. ${ }^{7}$ Pneumococci present at least three interchangeable variants which can be distinguished by their colony morphology into opaque, semitransparent, and transparent. The molecular basis of the phase variation is unknown but these phenotypes differ in their ability to colonise the nasopharynx. ${ }^{8}$ Nasopharyngeal cells bear a receptor, GlcNAc $\beta 1-3 \mathrm{Gal}$, which is recognised by transparent phase variants. Lung cells in the resting state bear two types of receptor, GalNc $\beta 1-4 \mathrm{Gal}$ and GalNc $\beta 1-3 \mathrm{Gal}$, which are recognised by both opaque and transparent types. Cytokine activated lung cells also express the resting receptors but also present platelet activating factor (PAF) receptors. Transparent phase variants are able to adhere to PAF receptors whereas opaque variants are not. Thus, adhesion to epithelial cells should be considered as a dynamic situation in which both bacteria and host cell receptors differ according to site of isolation or activation state.

\section{(2) Entry into the host}

Entry involves either direct invasion of the epithelial cells of a mucus membrane or passage between them followed by invasion of the deeper tissues. Not all pathogens invade; Vibrio cholerae causes disease by toxin production from within the intestinal lumen.

Invasion of epithelial cells by the gut pathogen Shigella flexneri has been investigated in some detailed and elegant studies. ${ }^{9}$ Entry of shigella into cells is triggered by three gene products IpaB (invasion plasmid antigen B), IpaC and IpaD. IpaB is a haemolysin responsible for the release of shigella from the vacuole into the cytoplasm where the organisms then move by polymerisation of host actin under the influence of the intracellular spread gene icsA. This 
motility results in the generation of protrusions from one cell into the next. The protrusion is 'clipped-off' to form a vacuole within the next cell. The double membranes of this vacuole are then lysed by the product of the icsB gene, the organisms are released into the cytoplasm and the cycle begins again. A note of caution is warranted here with regard to the use of tissue culture cells. Although the mechanism described above applies to HeLa cells, shigella cannot invade across a brush border. Further studies using animal models indicated that invasion was more complex. Shigella enter the colonic mucosa through $\mathrm{M}$-cells and then infect macrophages causing apoptosis programmed cell death). Apoptosis is mediated by the product of the ipaB gene. Inflammation resulting from the release of cytokines results in infiltration of phagocytes which damage the basal membrane and disrupt the epithelium. The brush border is disrupted and shigella invade the cells. This example highlights the need to use several approaches to understand the events occurring during pathogenesis.

\section{(3) Multiplication in the host}

Once in its specific niche the pathogen must multiply. The ability to multiply is a characteristic of all living organisms and the success of a pathogen depends on the degree to which it can multiply upon reaching its specific niche and secure its potential transmission to a new host. The speed of multiplication will also affect the type of disease caused. Rapid multiplication leads to acute disease whereas slow multiplication may be advantageous in chronic disease. Little is known of the molecular basis of multiplication within the host. The environmental factors and nutrients that determine growth rate in tissues remain largely unknown. Most detailed studies on factors controlling growth in vivo have concerned molecular mechanisms for overcoming iron restriction. Pathogens attempt to obtain iron by one of several mechanisms including (a) from haemoglobin as hemin or heme, for example $S$ pneumoniae, ${ }^{10}$ (b) directly from ferrated transferrin or lactoferrin, for example Neisseria gonorrhoeae, ${ }^{11}$ (c) indirectly from iron binding proteins by the production of siderophores, for example $E$ coli, ${ }^{12}$ (d) from intracellular iron stores, for example Mycobacterium tuberculosis. ${ }^{13}$

\section{(4) Interference with host defence systems}

To survive within the host the pathogen must either prevent the immune response or circumvent its action. There are many virulence factors associated with interference of host defence, including polysaccharide capsules, protein toxins and lipopolysaccharides.

Polysaccharide capsules interfere with the processes of phagocytosis and complement mediated bacterial killing. The importance of the capsule in the virulence of some organisms has been demonstrated at the molecular level. A non-capsular mutant of the pneumococcus generated by transposon mutagenesis was one million times less virulent than its capsular parent. ${ }^{14}$ The molecular mechanisms of activity of capsular polysaccharide still remain to be defined. It is known that sialyl groups on capsular polysaccharides of $E$ coli $\mathrm{K} 1$ and group B streptococci may prevent the activation of the complement pathway by these organisms. ${ }^{45}$ Antibodies to capsular polysaccharide usually confer protective immunity through opsonisation of bacteria promoting phagocytosis. Encapsulated pathogens are still major causes of human disease due to the production of diverse capsular types (for example pneumococcus) or to the capsule being non-immunogenic (for example $E$ coli $\mathrm{K} 1$ and Neisseria meningitidis group B). The nonimmunogenicity of these organisms may be due to the molecular structure of the polysaccharide subunits being similar to sugars found on host cells.
Pathogens may also produce toxins that interfere with the immune response. The pneumococcus, for example, produces pneumolysin. ${ }^{16}$ At high concentrations this membrane damaging toxin lyses all eukaryotic cells. At sublytic concentrations it has a range of effects on the cells and soluble molecules of the immune system. Pneumolysin inhibits the respiratory burst of phagocytes and also inhibits random migration and chemotaxis by these cells. ${ }^{17}$ The toxin inhibits antibody production by lymphocytes and blocks mitogen induced proliferation of B-cells. In vivo the toxin induces a large inflammatory response and this may be due to its ability to stimulate the production of inflammatory cytokines (interleukin-1 $\beta$ and tumour necrosis factor- $\alpha)^{18}$ and to activate the classical complement pathway. Activation of the classical complement pathway is due, at least in part, to the ability of the toxin to bind to the Fc portion of IgG. ${ }^{19}$ Molecular analysis has allowed the regions of the toxin responsible for these activities to be identified and modified. The role of the activities of the toxin have been investigated in the context of the whole bacterium ${ }^{20}$ by using gene replacement techniques to construct versions of the pneumococcus expressing altered versions of the toxin. ${ }^{21}$ These studies demonstrate the power of molecular analysis when used in combination with other techniques such as animal models in allowing the role of individual proteins, protein domains or even amino acids in the pathogenic process to be investigated.

Studies on the molecular basis of the activity of lipopolysaccharides (endotoxin) are not as advanced as studies with protein virulence factors. It is known that long $O$ side chains are required for serum resistance in $E$ coli and salmonella.

\section{(5) Damage to the host}

Damage to the host can be mediated either directly by production of toxins or indirectly by the induction of gross inflammation and immunopathologic reactions.

There is a wealth of information in the literature concerning the molecular action of bacterial protein toxins (reviewed in Alouf and Freer ${ }^{22}$ ). In some cases the contribution of the toxin to disease process is obvious (for example in cholera or tetanus) and the action of the toxins concerned is understood at the molecular level. Cholera toxin, for example, is an example of an ADP ribosylating toxin. The enzymatic action of the toxin results in the ADP ribosylation of a regulatory $G$ protein of the adenylate cyclase complex in enterocytes. This results in increased levels of cAMP which in turn alters ion transport across the epithelium and leads to the diarrhoea which is the key feature of the disease. The heat labile toxin of $E$ coli works in a similar manner to cholera toxin. Other examples of ADP ribosylating toxins include pertussis toxin, diphtheria toxin and toxin A of Pseudomonas aeruginosa. The effects of these toxins vary according to the cellular target of ADP ribosylation. Diphtheria and toxin A inhibit protein synthesis while pertussis toxin uncouples signal transduction. Other toxins are proteases. Tetanus toxin is a zinc protease that cleaves synaptobrevin, a protein involved in neurotransmitter release. Another large group of toxins are known as the membrane damaging toxins. These include pore forming proteins such as Staphylococcus aureus alpha toxin and thiol-activated toxins including pneumolysin. The molecular mechanisms of action of some activities of these toxins have been elucidated, but others and contribution to disease of the process of pore formation is still unclear.

Stimulation of inflammation may occur due to the inappropriate or excessive production of cytokines or activation of the complement pathway. Inappropriate cytokine production or activation of the complement cascade may 
be triggered by bacterial toxins such as pneumolysin. Bacterial cell wall components also stimulate cytokine production. Stimulation of inflammatory cytokine production by lipopolysaccharide of Gram negative bacterial cell walls mediates endotoxic shock. Release of inflammatory cell wall fragments from the pneumococcus during autolysis mediates inflammation and data suggest that this inflammation is the major contributing factor to pathology in pneumococcal meningitis. Treatment of pneumococcal meningitis with cell wall active antibiotics such as penicillin may have the short term effect of promoting inflammation and it has been suggested that these antibiotics should be used in conjunction with anti-inflammatory agents. ${ }^{23}$ The molecular mechanisms of induction of cytokines by lipopolysaccharide and Gram positive cell walls are now beginning to be understood at the molecular level and have been reviewed. ${ }^{74}$

Immunopathologic reactions may also lead to damage to the host. These reactions occur due to bacterial antigens including the production of antibodies that are cross reactive to human structures as is seen for example in endocarditis after infection with group A streptococci. Glomerulonephritis can also occur after streptococcal infection and is due to the deposition of immune complexes in the kidney. The molecular determinants of some of these reactions have been established. The $\mathrm{M}$-protein of streptococci, for example, has been shown to share epitopes with antigens expressed in heart tissue. ${ }^{25}$ Ankylosing spondylitis may be caused by antibodies to klebsiella reacting with antigens expressed by lymphocytes from individuals with the HLA B27. ${ }^{26}$

\section{Regulation of virulence}

When it encounters a host, a pathogen must adapt to changing environments and express appropriate virulence factors. Virulence genes may be regulated in response to a range of environmental stimuli including $\mathrm{pH}$, temperature, oxygen tension, and inorganic metal ion concentration. Knowledge about the molecular basis of virulence gene regulation is rapidly increasing. The commonest mechanism involves two component regulatory systems in which one component (the sensor) detects the environmental stimulus while the other (the reponder, usually a DNA binding protein) is responsible for altering gene expression. The sensor protein is usually a membrane spanning kinase which autophosphorylates on stimulation. The phosphate is then transferred to the response regulator proteins which then affect gene expression. Examples of this type of system are regulation of permeability in $E$ coli in response to osmotic stimuli (EnvZ/OmpR) and regulation of motor control in $E$ coli chemotaxis (CheA/CheY, CheB). These types of system, which have been comprehensively reviewed, ${ }^{27}$ have common features but differ in their exact mechanisms.

Bacterial pathogens produce a range of molecules that allow them to cause disease via the five stages described above. It should be emphasised that these five stages are not discrete steps and the interaction of the pathogen with its host is dynamic. The pathogen continually monitors its environment and produces virulence factors according to the signals it receives. There is also a host contribution to the process such that genetic differences between individuals will make one host environment different to another and affect the interactions and signals that occur between the pathogen and its environment. An understanding of the events that occur at the molecular level both in the action of individual virulence factors and in the coordinate regulation of virulence as a whole is a continuing aim that will be aided by the new trend of total genome sequencing of pathogens. An understanding of the molecular events involved in the disease process will allow us to generate new weapons to use in the continuing battle against infectious diseases.

T J MITCHELL

Division of Infection and Immunity,

IBLS, foseph Black Building,

University of Glasgow,

Glasgow G12 8QQ

1 Smith H. Biochemical challenge of microbial pathogenicity. Bacteriology Reviews 1968;32:164-84

Beachy EH. Bacterial adherance: adhesin-receptor interactions mediating attachment of bacteria to mucosal surfaces. F Infect Dis 1981;143:325-45.

3 Hacker J. Role of fimbrial adhesins in the pathogenesis of Escherichia coli infections. Can 7 Microbiol 1992:38:720-7.

4 Finlay BB, Falcow S. Common themes in microbial pathogenicity. Microbiol. Rev. 1989;53:210-30.

5 Smyth CJ, Smith SGJ. Bacterial fimbriae: variation and regulatory mechanisms. Symposia of the Society for General Microbiology 1992;49:26798

6 Morschhauser I, Hoschutzky H, Jann K, et al. Functional analysis of the sialic acid binding adhesin SfaS of pathogenic Escherichia coli by site specific mutagenesis. Infect Immun 1990;58:2133-8.

Cundell D, Masure HR, Tuomanen EI. The molecular basis of pneumococcal infection: a hypothesis. Clin Infect Dis 1995;21 (suppl 3):S204-12.

8 Cundell DR, Weiser JN, Young A, et al. Relationship between colonial morphology and adherance in Streptococcus pneumoniae. Infect Immun 1995; 63:757-61

9 Sansonetti PJ. Molecular and cellular biology of invasion by Shigella flexneri and other enteroinvasive pathogens. Symposia of the Society for General Microbiology 1992;49:47-60.

10 Tai SS, Lee C-J, Winter RE. Hemin utilization is related to virulence of Streptococcus pneumoniae. Infect Immun 1993;61:5401-5

11 McKenna WR, Mickelsen PA, Sparling PF, et al. Iron uptake from lactoferrin and transferrin by Neisseria gonorrhoeae. Infect Immun 1988;56:78591 .

12 Neilands JB, Bindereif A, Montgomerie JZ. Genetic basis of iron assimilation in Escherichia coli. Curr Top Microbiol Immunol 1985;118:17995.

13 Lepper AWD, Wilks CR. Intracellular iron storage and pathogenesis of paratuberculosis. Comparison with other mycobacterial, parasitic or infectious conditions of veterinary importance. F Comp Pathol 1988;98:31-53.

14 Watson DA, Musher DM. Interuption of capsule production in Streptococcus pneumoniae type serotype 3 by insertion of Tn916. Infect Immun 1990; 58:3135-8.

15 Jann K, Jann B. Capsules of Escherichia coli: expression and biological significance. Can. F Microbiol 1992;38:705-10

16 Paton JC, Andrew PW, Boulnois GJ, et al. Molecular analysis of the pathogenicity of Streptococcus pneumoniae:the role of pneumococcal proteins. Annu Rev Microbiol 1993;47:89-115.

17 Paton JC, Ferrante A. Inhibition of human polymorphonuclear leukocyte respiratory burst, bactericidal activity, and migration by pneumolysin. Infect Immun 1983;41:1212-6.

18 Houldsworth S, Andrew PW, Mitchell TJ. Pneumolysin stimulates production of tumor necrosis factor alpha and interleukin-1beta by human mononuclear phagocytes. Infect Immun 1994;62:1501-3.

19 Mitchell TJ, Andrew PW, Saunders FK, et al. Complement activation and antibody binding by pneumolysin via a region of the toxin homologous to a antibody binding by pneumolysin via a region of the toxin hon

20 Rubins JB, Charboneau D, Fasching C, et al. Distinct role for pneumolysin's cytotoxic and complement activities in the pathogenesis of pneumococcal pneumonia. Am $\mathcal{F}$ Respir Crit Care Med 1996;153:1339-46.

21 Berry AM, Alexander JE, Mitchell TJ, et al. Effect of defined point mutations in the pneumolysin gene on the virulence of Streptococcus pneumoniae. Infect Immun 1995;63:1969-74.

22 Alouf JE, Freer JH, eds. Sourcebook of bacterial protein toxins. London: Academic Press, 1991

23 Kornelisse RF, deGroot R, Neijens HJ. Bacterial meningitis: mechanism of disease and therapy. Eur f Pediatr 1995;154:85-96.

24 Proctor RA, Denlinger LC, Bertics PJ. Lipopolysaccharide and bacterial virulence. In: Roth JA, Bolin CA, Brogden KA, et al, eds. Virulence mechanisms of bacterial pathogens. Washington: Academic Press, 1995:173-94.

25 Sargent SJ, Beachey EH, Corbett CE, et al. Sequence of protective epitopes of streptococcal M proteins shared with sarcolemmal membranes. f Immuof streptococcal M proter
nol $1987 ; 139: 1285-90$

26 Zabrinski JB. Immunopathological mechanisms in bacterial-host interactions. Transactions of the Royal Society of London Series B 1983;303:177-87.

27 Hoch JA, Silhavy TJ, eds. Two-component signal transduction. Washington: ASM Press, 1995.

\section{Commentary}

The issues discussed by Professor Mitchell raise some important questions about the characteristics of the many human diseases that occur as a consequence of infection.

Micro-organisms have evolved alongside humans and, indeed, are able to evolve much more rapidly due to their short generation times. The nature of their relationships with us vary from, at one extreme, imperceptible parasitism (for example commensal colonisation of the skin and mouth) or even full blown symbiosis (for example the mitochondria in all our cells-thought to derive from exogenous microbes) to overwhelming illness and death at 
the other (for example septicaemia due to Neisseria meningitidis or infection with HIV), with examples of infections of every conceivable site, rate, and severity in between.

Upon first consideration, it seems surprising that "we" and "they", driven by the same fundamental aims to survive and multiply, should have thrown up such a myriad of diverse relationships. However, the existence of so many possible distinct mechanisms of transmission and sites of colonisation explains the large number of distinct niches that exist for micro-organisms.

More puzzling is why so many infections are virulent (that is cause disease) at all. Sometimes it is fairly obvious how induction of certain symptoms of disease contributes to the survival and spread of invading micro-organisms (for example diarrhoea in cholera and sneezing in rhinovirus infection). However, a "purpose" for disease features is often less clear. For example it is hard to see how the survival of Streptococcus pneumoniae is enhanced by causing countless episodes of acute ear pain in preschool children and occasional episodes of meningitis. Some well known infectious diseases (for example tetanus and human infections with Pseudomonas spp) would appear to be the results of extraordinary and largely irrelevant excursions into the human for microbes whose modus vivendi is inhabiting the soil and stagnant water.

Of course, as doctors, we tend to focus our attention on disease-producing micro-organisms rather than the many others which have taken an evolutionary stance not unlike that of sheep-achieving enormous success in terms of sheer numbers by being useful, keeping quiet, not causing problems, and putting up with rough treatment at times. Most of us have learned to adopt what could be termed the "microbe centred" view of infectious diseases, namely that these are examples of "invaders" penetrating and colonising the human host and doing damage along the way. As Mitchell's article points out, the manifestations of disease are as often as not due to the host response, or over-response, to the situation.

\section{Growing interest in overgrowth}

Congenital malformations or complex malformation syndromes are frequently associated with growth failure and have been the subject of much research and discussion in the paediatric literature. The less common overgrowth syndromes (OGSs) have until recently received little attention. The disordered growth in OGSs is, however, a primary anomaly and, unlike growth failure, is not explained away as a secondary phenomenon as is the case with many other complex syndromes. OGSs may therefore provide a fascinating window into the mechanisms of growth and the consequences of the failure of this regulation.

Ancient literature has many references to giants such as Goliath, Polyphemus, Gargantua, or the Patagonian giants. Whether real or fictional, these reports show that such patterns have been present throughout history and serve to highlight two of the central issues-what is a "true overgrowth syndrome and how many overgrowth syndromes exist?"

Previously, overgrowth patterns were often categorised as primary or secondary. In primary disorders, the growth would be an intrinsic (unexplained) feature of the condition secondary to cellular hyperplasia, whereas in secondary disorders an identifiable cause, often endocrino-
Clearly eukaryotic organisms evolved a fundamental principle of survival - manifest as the immune responsevery early on, namely: “if it's inside me but isn't me, kill it before it kills me". This process remains the central dogma of our immunity because, despite important exceptions such as mitochondria and long term colonisation with herpes viruses and mycobacterium tuberculosis which (usually) don't do any harm, owners of immune systems which give invading microbes the benefit of the doubt don't survive well.

Our immune responses set clear boundaries to the hoards of microbes that surround us (outside and inside). Our secreted protein and phagocyte defences endeavour to inflict instant death on the invader and our specific immunity acts as a slower but highly organised search and destroy machinery for viruses or larger microbes which succeed in penetrating our initial defences.

Thus, infectious diseases, when they occur, are the result of the interaction between microbe and host. In other words, infection and immunity are two sides of the same coin and cannot be studied legitimately in isolation from each other.

Experience with vaccines has already shown the potential power of inducing host responses in the prevention of infectious diseases. As knowledge of the molecular details of our interactions with micro-organisms continues to grow, this will certainly also lead to new interventions designed specifically to treat disease by modifying the host response or by interfering with microbe-host interactions, as well as to additional conventional agents designed to inhibit or kill the microbe.

ADAM FINN Sheffield Institute for Vaccine Studies, Department of Paediatrics, Sheffield Children's Hospital, Western Bank, Sheffield S10 $2 T H$

logical, would be expected to result in growth excess. ${ }^{1}$ The limitations of this rather simplistic differentiation have been illustrated by the identification of "novel" growth factors in a number of OGSs, such as Beckwith-Wiedemann syndrome (BWS) and Simpson-Golabi-Behmel syndrome (SGBS). In these disorders, abnormalities of insulin-like growth factor II (IGF II) and glypican 3 have been implicated. ${ }^{2}$ It would seem that if the term secondary growth excess is still relevant, it should be limited to situations dependent on extrinsic growth promoters, such as fetal macrosomia secondary to maternal diabetes and hyperglycaemia and subsequent fetal hyperinsulinaemia. For the foreseeable future most "primary" OGSs will be classified by a process of clinical assessment and/or laboratory exclusion with the possible exceptions of BWS and SGBS, where clinical application of molecular tests might be feasible within a few years.

The constraints of this review preclude the discussion of another group of overgrowth patterns: those syndromes exhibiting regional/tissue specific overgrowth (table 1). These may provide further clues to specific growth promoters, and will have to be considered when developing a model of overall growth control. 


\section{Endocrinological and metabolic disorders with an overgrowth component}

Abnormalities of the hypothalamic pituitary adrenal axis may result in early overgrowth. A number of these are autosomal recessive and the most common is congenital adrenal hyperplasia due to 21-hydroxylase deficiency. In untreated cases, the production of excess 7-hydroxyprogesterone and androgenic steroids results in increased growth from birth and precocious puberty secondary to the anabolic effects of the steroids. ${ }^{4}$ Secretory tumours within this axis may also result in similar overgrowth patterns. A much rarer recessive adrenal disorder is adrenocorticotrophic hormone receptor deficiency. This may present with symptoms suggestive of adrenal failure or overgrowth, or both, and prompt treatment of the adrenal insufficiency is of obvious importance. ${ }^{5}$

The aetiology of the overgrowth and endocrinological confirmation of each of the above is clear. This has not always been the case for disorders with proved endocrinological abnormalities, for example, Seip-Berardinelli lipodystrophy syndrome. This autosomal recessive condition appears to show insulin resistance, but normal pituitary and adrenal function on formal testing. The growth excess can be striking (considerably more than 97th centile), and appears to be more than would be expected from the postulated anabolic component of the syndrome. After some 30 years of research, the mechanism of overgrowth and its link to insulin resistance is only now becoming clearer. ${ }^{6}$

One further condition that may rarely present with overgrowth, which is important not to miss because of the neurological and genetic implications, is the recessive condition, mucopolysccharidosis type III (Sanfilippo's syndrome). ${ }^{7}$ Early literature indicates that the excess growth is only apparent in the first two to three years of life, and that the regression and mental handicap is obvious by this stage. This is in fact frequently incorrect, and I have personal experience of a 6 year old patient over the 90th centile for all growth measurements, who was then only starting to show a decline of intellectual abilities into the range of mild mental handicap.

\section{Congenital malformation syndromes with} overgrowth as the major intrinsic component

The majority of conditions with "primary" overgrowth are poorly understood but are part of an ever increasing list of possible diagnoses. The current London dysmorphology database lists 283 conditions with either macrocephaly, obesity, increased birth weight, or excess stature. ${ }^{8}$ Personal experience in excess of 300 children, is that as many as $50 \%$ do not easily sit within the diagnostic categories currently recognised.

Any diagnostic assessment must include taking an adequate family history and measurements of the nuclear family, as the largest single factor is without doubt familial large stature or early maturation. The presence of some additional sign or symptom within an individual does not necessarily require a syndrome diagnosis because single malformations, or some degree of learning difficulty, is present in up to $10 \%$ of the population. ${ }^{9}$

All possible diagnostic considerations will not be covered within this annotation, however the reader is referred to the excellent review of Cohen. ${ }^{1}$ Tables 1 and 2 (modified from Cole and Hughes ${ }^{10}$ ) also list some of the range of regional and generalised overgrowth disorders.

\section{BWS and SGBS-two OGSs but a common aetiological pathway}

BWS, first described in $1963,{ }^{11}$ has provided much of the recent impetus for research into overgrowth patterns. It has a reported frequency of one in 13700 from a study in
Table 1 Examples of regional or tissue specific overgrowth

Autosomal dominant macrocephaly

Macrocephaly cutis marmorata telangiectasia

Neurofibromatosis

Proteus syndrome

Encephalocraniocutaneous lipomatosis

Hemihypertrophy

Klippel-Trénaunay-Weber syndrome

Maffucci's syndrome

Olliers syndrome

Prader-Willi syndrome

Cohen's syndrome

Carbohydrate glycoprotein deficiency

Fragile X syndrome

Trisomy 8 mosaicism

Jamaica. ${ }^{12}$ I would, however, be concerned of the influence of the high frequency of umbilical hernias (also known to be associated with an increased familial frequency of exomphalos) in this population. ${ }^{13}$ This might have led to over diagnosis, or might indicate that the population as a whole had a higher than average frequency of some of the predisposing mechanisms of BWS.

In BWS, the three main components are abdominal wall defects (exomphalos=E), macroglossia $(\mathrm{M})$, and increased birth weight or growth $(\mathrm{G})$ present in $80 \%, 88 \%$, and $97 \%$ respectively, resulting in the alternative name EMG. ${ }^{14}$ The paediatric relevance of BWS is maintained because approximately $4-7.5 \%$ of patients develop childhood tumours, most commonly Wilms' tumours. ${ }^{114}$ Hemihypertrophy, present in $13-24 \%$ of patients with BWS, ${ }^{14}$ is reported in $40 \%$ of cases with tumours, ${ }^{1}$ therefore the presence of hemihypertrophy appears to be associated with an increased risk of tumourigenesis.

Growth in BWS is usually most marked during the first few years of life. This is compatible with current evidence that IGF II, the likely growth factor in BWS, has its greatest influence during this period. By contrast, final height in many individuals with BWS is within the normal range, although there are exceptions. There is even a suggestion of a bimodal pattern, with a small group showing excessive height. It will be of interest to see if specific molecular mechanisms are associated with different growth patterns.

Despite neonatal symptoms, which can include feeding and respiratory difficulties and very rarely neonatal death, the large majority of survivors have few severe nonmalignant health problems. Intellectual development is believed to show the same distribution as the general population, with the possible exception of patients with extreme or untreated hypoglycaemia or with unbalanced chromosomal translocations.

Of particular genetic interest are the mechanisms underlying BWS. It is estimated that approximately $15 \%$ of families show autosomal dominant inheritance, ${ }^{14}$ and these show linkage to the chromosome region $11 \mathrm{pl} 5.5$, including the insulin IGF II gene loci. ${ }^{15}$ Further studies, reviewed by

Table 2 Generalised overgrowth conditions

Familial/sporadic constitutional gigantism

Familial/sporadic precocious maturation

Bannayan-Riley-Ruvalcaba syndrome

Marfan's syndrome

Beckwith-Wiedemann syndrome

Marshall-Smith syndrome

$\mathrm{MOMO}^{\star}$ syndrome

Nevo's syndrome

Perlman's syndrome

Seip-Barardinelli syndrome

SGBS

SS

WSS

Congenital adrenal hyperplasia

Pituatry/adrenal and gonadal secreting tumours

Sanfilippo's syndrome

Klinefelter's syndrome

${ }^{\star} \mathrm{MOMO}=$ macrosomia-obesity-macrocephaly-ocular anomalies 
Table 3 Comparison of the phenotypes of BWS and SGBS

\begin{tabular}{lll}
\hline & $B W S$ & $S G B S$ (in boys) \\
\hline Macroglossia & ++ & ++ \\
Abdominal wall defects & ++ & + \\
Visceromegaly & ++ & ++ \\
Hypoglycaemia & ++ & + \\
Embryonal tumours & $+/(+)$ & $+/(+)$ \\
Ear creases & ++ & ++ \\
Ear pits & + & $?$ \\
Flammeus naevus & ++ & ++ \\
Cleft lip/palate & ++ & + \\
Groved tongue/lip & $?$ & ++ \\
Facial outline & Round & Square \\
Coarsening facial gestalt & + & ++ \\
Genital anomalies & ++ & + \\
Congenital heart disease & ++ & + \\
Additional nipples & $?$ & + \\
Postaxial polydactyly & $(+)$ & + \\
Syndactyly & $(+)$ & + \\
Short/squared distal phalynx & $?$ & ++ \\
Final height increased & + & ++ \\
\hline Approximate frequency of anomalies: & $++>50 \%,+5-50 \%,(+)<5 \%, ?$ frequency \\
unclear but probably rare or absent. & &
\end{tabular}

Mannens et al, showed that paternal duplications, maternal translocations, and paternal uniparental disomy (the presence of only paternal chromosome material) involving $11 \mathrm{pl} 5.5$ result in BWS. ${ }^{16}$ There is evidence that the phenotype results from overexpression of IGF II, a gene usually only expressed on chromosomes of paternal origin. ${ }^{2}$ Recent papers have shown that mutations within $\mathrm{p} 57^{\mathrm{KIP} 2},{ }^{17}$ or disruption of the gene KVLQT $1,{ }^{18}$ which both map proximal to IGF II at $11 \mathrm{pl} 5.5$, will result in the BWS phenotype. In both instances the maternally inherited gene is affected. At least one family with a translocation disrupting KVQLT1 had biallic IGF II expression, while p $57^{\mathrm{KIP} 2}$ may be involved in a common pathway with IGF II. A p $57^{\mathrm{KIP} 2}$ gene "knockout" mouse, ${ }^{19}$ and subsequent mutation studies of KIP2 in humans, also results in a BWS phenotype, but once again only if the maternal allele is affected. ${ }^{20}$ There also appears to be some early evidence for genotype/phenotype correlations with $\mathrm{p} 57^{\mathrm{KIP} 2}$ mutation carriers having a high frequency of abdominal wall defects (five out of seven had exomphalos, one out of seven had an umbilical hernia) but no embryonal tumours, ${ }^{20}$ whereas uniparental disomy $11 \mathrm{pl} 5.5$ may be associated with a slightly greater risk of tumourigenesis. ${ }^{16}$

This phenomenon of imprinting (the regulation of gene expression dependent on parent of origin) is believed to be important in numerous different conditions with disordered growth including Prader-Willi syndrome, Angelman's syndrome, Russell-Silver syndrome, and certain tumours, and has therefore been the subject of intense investigation. $^{2122}$

During research into BWS, clinicians noted the striking phenotypic overlap with SGBS, an X linked overgrowth disorder (table 3). ${ }^{23}{ }^{24}$ In the report of Thorburn et al the diagnosis of SGBS in some, or all, of the three boys (all of whom died in infancy and had additional malformations recognised in SGBS) remains a possibility, and is one further source of error which could result in overestimation of the incidence in BWS in their paper. ${ }^{12}$

After the identification of glypican 3 mutations as the cause of SGBS, ${ }^{3}$ subsequent antibody studies showed there was cross reaction of binding between the ligands for glypican and IGF II receptors. ${ }^{325}$ This in turn might explain the striking phenotypic overlap and also raised the possibility of further diagnostic errors in the literature or clinical setting. The latter has significant implications for genetic counselling.

An additional consideration is the existence of an undiagnosed group of patients, as reported in the paper by Morrison et al. $^{26}$ They described "non"-BWS patients with overexpression of IGF II. I would suggest that the presence of overgrowth and nephromegaly in these patients might represent the mild end of the spectrum of BWS. An alternative explanation is that many macrosomic babies have some underlying mechanism which results in abnormalities of IGF II expression, the BWS phenotype being just one of the resultant outcomes. If the outcome is not the BWS phenotype, it raises the fascinating possibility that overexpression of IGF II might explain the excess of neuroblastoma and Wilms' tumours in babies weighing over $4000 \mathrm{~g} .{ }^{27}$ As we start to unravel the mechanisms behind BWS and SGBS it appears that a more intriguing set of questions are raised.

While molecular studies for glypican 3 and IGF II are still at an early stage, it seems likely that within the next 2-3 years these will become part of the routine investigation for BWS and SGBS in an effort to confirm the diagnosis and the recurrence risk, and perhaps even help predict the individual natural histories.

Sotos' syndrome (SS), Weaver-Smith syndrome (WSS), and other overlapping phenotypes

My own experience, and that within our department, is that referrals of SS and BWS are approximately equal although this figure may be biased by my own research interests. However, it is probable that SS is at least the second most common overgrowth disorder after BWS.

SS was first reported in $1964,{ }^{28}$ although I suspect the first literature case may be the report of Schlesinger in 1932. ${ }^{29}$ The clinical features are of prenatal and postnatal overgrowth, developmental delay, characteristic facial appearance, and an advanced bone age. Apart from the subjective assessment of facial gestalt (table 4) and relative frequencies of developmental delay, the remaining diagnostic criteria are not only features of BWS and SGBS, but also the WSS and Marshall-Smith syndrome (MSS). ${ }^{30} 31$ Furthermore, a number of less frequent signs such as hernias, minor skeletal anomalies, and tumour predisposition are probably present to varying degrees in each of the above disorders. Currently the majority of opinion splits SS, WSS, and MSS into three distinct syndromes.

The growth in SS is most marked during the first 4-5 years of childhood, although may be "masked" during the first 36 months of life if complications secondary to prematurity, hypotonia, poor feeding, or respiratory difficulties are present. The two growth variables most significantly increased are length and occipitofrontal circumference, whereas weight is often lower than would be expected for the patients stature. ${ }^{32}$ Final height is commonly below or close to the $+2 \mathrm{SD}$. This appears to be

Table 4 Facial gestalt of SS, WSS, and MSS

SS

Dolichocephaly

Tall bossed forehead

High frontal hairline

Slow/sparse hair growth fronto-parietal areas

Pear shaped facial outline

Lengthening face in childhood

Long jaw

Down slant palpebral fissures

Red facial colouring

WSS

Broad rounded forehead

Round facial outline

Small prominent chin

Rounded full mid face

Long prominent philtrum

Large ears

MSS

Fine facial bones

Prominent eyes

Thin gaunt facies

Anteverted nares

Micrognathia 
particularly true of girls whose growth often stops earlier than their peers after a relatively early puberty. This pattern appears more variable in boys, but still very few exceed or even approach $+3 \mathrm{SD}$ (Agwu et al in preparation). It is the authors experience that while careful monitoring of growth, bone age, and pubertal status is advisable, therapeutic intervention is almost never necessary to obtain an "acceptable" final height.

SS was originally incorrectly reported to have a high frequency of mental handicap (88\%). ${ }^{33}$ It is now clear that the figure is lower, and Finegan et al reported that $78 \%$ of children have an IQ above $70 .^{31}$ This still remains one of the highest figures for OGSs and is often associated with significant behavioural problems. ${ }^{34}$ Other significant medical complications are individually uncommon. ${ }^{32}$

Despite the similarities with WSS and MSS, these two conditions appear to exhibit higher frequencies of severe medical complications, including skeletal anomalies and infant death. Surprisingly, personal experience of the three older cases of WSS (two adults and one adolescent) and the two oldest literature cases of MSS is that intellectual abilities have been within, or near to, the normal range in all these individuals. ${ }^{35}$ This might be fortuitous, as significant intellectual impairment has been documented in both disorders.

The range of final heights in WSS remains unclear, however three literature reports of adults with WSS, and my own experience of two adult patients, may suggest that heights, significantly in excess of $+2 \mathrm{SD}$, are more common than in SS. ${ }^{30}{ }^{32}$ It should be stressed that ascertainment bias could be very relevant in four out of five of these cases.

\section{The genetics of OGSs}

The genetics of BWS is that the majority are sporadic, but approximately $15 \%$ follow autosomal dominant inheritance. In my experience of approximately 200 cases of SS, three cases, and one of 15 cases of WSS segregated in an autosomal dominant fashion, ${ }^{30}$ the remainder are sporadic. Unlike BWS, to date there has been no consistent region of chromosomal alteration in the other OGSs, and a study of uniparental disomy in SS was negative within the limitations of the study. ${ }^{37}$ The genetics therefore remain obscure in the majority of OGSs.

The clinical similarities among the OGSs should intrigue, yet alert, the researcher to the issue of whether the OGSs should be "lumped" or "split". It seems certain that only as the molecular basis unfolds will it become clear if the disorders are differing ends of the same spectrum or separate conditions. Could it be that they will be allelic variations in the same gene, such as in the RET oncogene which results in the different multiple endocrine neoplasia II syndromes and Hirschsprung's disease, ${ }^{38}$ or mutations in the same fibroblast growth factor gene associated with the different craniosynostosis syndromes such as Apert's, Pfeiffer's, Crouzon's, and Jackson-Weiss? ${ }^{39}$ Or perhaps the different OGSs will be due to mutations within a group of genes like the fibroblast growth factor I, II, and III genes, each associated with syndromes including the feature of craniosynostosis, ${ }^{39}$ or the different fibrillin genes which are the cause of Marfan's syndrome (fib 1), ${ }^{40}$ congenital contractural arachnodactyly (fib 2), ${ }^{41}$ and ShprintzenGoldberg (fib 1). ${ }^{42}$ While these are possible mechanisms, the only precedent in OGSs is in BWS and SGBS. In these two conditions, none of the above mechanisms apply, but rather two different genes interact on the same pathway. ${ }^{25}$
Different overgrowth patterns-different genetic mechanisms

AUTOSOMAL DOMINANT MACROCEPHALIES

The autosomal dominant macrocephalies are one further overgrowth spectrum which appear to show a perplexing degree of pleiotropy and heterogeneity. ${ }^{43}$ They may also overlap with intriguing sporadic macrocephaly conditions such as the macrocephaly, telangiectasia, and cutis mamorata syndrome. Unravelling the mechanisms behind features associated with macrocephaly, such as vascular anomalies ${ }^{43}$ or autism, ${ }^{44}$ could be a further fruitful area of research related to overgrowth disorders.

MOSAIC DISORDERS

This text so far has only considered conditions that I believe to be non-mosaic mutations. Disorders such as Proteus' syndrome and McCune-Albright syndrome, are most likely, or have already been proved to be, due to somatic mutations, and if present in a non-mosaic syndrome it is postulated that they would be lethal in most situations.

Molecular investigations of patients with McCuneAlbright syndrome have confirmed the presence of mosaic mutations in Gs $\alpha$ gene. ${ }^{45}$ Patients with McCune-Albright syndrome show quite remarkable early overgrowth. Much of this appears to be secondary to the effects of a strikingly early puberty. It is clear, however, that the G proteins are a family of signal transducers and have a regulatory role on many different endocrinological and growth factor pathways. The growth and endocrine role and the recognition of de novo mutations makes this group of genes interesting potential candidates for OGSs such as SS and WSS.

\section{Conclusions}

OGSs offer the opportunity to study prenatal and postnatal growth in normal tissues, and may show how abnormal growth may predispose to tumour development. It is also of great interest that many of the genes involved in growth disorders are regulated and (for example, imprinted) dependent upon their parent of origin, which may be highly significant in fetal growth.

The recognition of new OGSs is still occurring and yet as many as $50 \%$ of cases do not appear to fall neatly into any recognised patterns. However, the aetiology of the clinical overlap between diagnosed and currently undiagnosed syndromes may become apparent as the underlying genetic mechanisms become clearer. As this molecular understanding remains incomplete, it is important to try and identify on clinical grounds the specific "syndrome pattern" where possible, as the natural history and genetics may vary considerably.

The author would like to acknowledge the support provided by Action Research which enabled collection of much of his data on overgrowth syndromes and stimulated a lasting interest and Professor Eamonn Maher for his many helpful comments on the annotation.

West Midlands Regional Clinical Genetics Service,

TREVOR COLE

Clinical Genetics Unit,

Birmingham Women's Hospital NHS Trust,

Edgbaston,

Birmingham B15 2TG

1 Cohen MM Jr. A comprehensive and critical assessment of overgrowth and overgrowth syndromes. In: Harris H, Hirschhorn K, eds. Advances in human genetics. New York: Plenum Press, 1989;18:181-303.

2 Weksberg R, Shen DR, Fei YL, Song QL, Squire J. Disruption of insulin like growth factor II imprinting in Beckwith-Wiedemann syndrome. Nat Genet 1993;5:143-50.

3 Pilia G, Hughes-Benzie RM, Mackenzie AK, et al. Mutations in GPC3, a glypican gene, cause the Simpson-Golabi-Behmel overgrowth syndrome.

4 Donohue PA, Parker K, Migeon CJ. Congenital adrenal hyperplasia. In: Scriver CR, Beaudet AL, Sly WS, Valle D, eds. 7th Ed. The metabolic and molecular basis of inherited disease. New York: McGraw-Hill, 1995;2:2929-66. 
5 Weber A, Toppari J, Harvey RD, et al. Adrenocorticotrophin receptor gene mutations in familial glucocorticoid deficiency: relationship with clinical features in four families. F Clin Endocrinol Metab 1995;80:56-71.

6 Seip M, Trygstad O. Generalised lipodystrophy, congenital and acquired (lipoatrophy). Acta Paediatr Suppl 1996;413:2-28.

7 Neufeld EF, Muenzer J. The mucopolysaccharidoses. In: Scriver CR, Beaudet AL, Sly WS, Valle D, eds. 7th Ed. The metabolic and molecular basis of inherited disease. New York: McGraw-Hill, 1995;2:2465-94.

8 Winter RM, Baraitser M. London dysmorphology database. Oxford: Oxford University Press, 1993

9 Rimoin DL, Connor JM, Pyeritz RE. Nature and frequency of genetic disease. In: Rimoin DL, Connor JM, Pyeritz RE, eds. 3rd Ed. Emery and Rimoin's principles and practice of medical genetics. New York: Churchill Livingstone, 1996;1:31-4.

10 Cole TRP, Hughes HE. Sotos syndrome. F Med Genet 1990;27:571-6.

11 Beckwith JB. Extreme cytomegaly of the adrenal fetal cortex, omphalocele, hyperplasia of the kidneys and panceas, and Leydig-cell hyperplasia: another
syndrome? Presented at the Annual Meeting of the Western Society for syndrome? Presented at the Annual Mee
Pediatric Research, Los Angeles, 1963.

12 Thorburn MJ, Wright ES, Miller CG, Smith-Read EHM. Exomphalosmacroglossia-gigantism syndrome in Jamaican infants. Am $\mathcal{f}$ Dis Child 1970;119:316-21.

13 Evans AG. Comparative incidence of umbilical hernias in colored and white infants. F Natl Med Assoc 1944;33:158

14 Elliott M, Bayly R, Cole T, Temple IK, Maher ER. Clinical features and natural history of Beckwith-Wiedemann syndrome: presentation of 74 new cases. Clin Genet 1994:46:168-74.

15 Koufos A, Grundy P, Morgan K, et al. Familial Wiedemann-Beckwith syndrome and a second Wilms' tumour locus both map to $11 \mathrm{pl5}$.5. Am f Med Genet 1989;44:711-9.

16 Mannens M, Hoovers J, Redeker E, et al. Parental imprinting of human chromosome region 11pl5.3-pter involved in the Beckwith-Wiedemann syndrome and various human neoplasia. Eur 7 Hum Genet 1994;2:3-23.

17 Hatada I, Ohashi H Fukushima Y. An imprinted gene p5 $7^{\mathrm{KIP} 2}$ is mutated in Beckwith-Wiedemann Syndrome. Nat Genet 1996;14:171-3.

18 Lee MP, Hu R-J, Johnson LA, Feinberg AP. Human KVLQT1gene shows tissue-specific imprinting and encompasses Beckwith-Wiedemann syntrome chromosomal rearrangements. Nat Genet 1997;15:181-5.

19 Pumin Z, Liegeois NJ, Wong K, et al. Altered cell differentiation and proliferation in mice lacking p57kip2 indicates a role in Beckwith-Wiedemann eration in mice lacking p57kip2 in

20 Lam WWK, Hatada I, Ohishi S, et al. Analysis of germline p57KIP2 mutations in the imprinting disorder Beckwith-Wiedemann syndrome (BWS) provides a genotope-phenotype correlation. Am F Hum Genet 1997;61: (suppl 3)

21 Clarke A. Genetic imprinting in clinical genetics. Development 1990;(suppl): 131-9.

22 Feinberg AP. Geneomic imprinting and gene activation in cancer. Nat Genet 1993;4:110-3

23 Hughes-Benzie RM, Hunter A, Allanson J, Mackenzie A. Simpson-GolabiBehmel syndrome associated with renal dysplasia and embryonal tumour: localisation of a gene to Xqcen-q21. Am f Med Genet 1992;43:428-35.

24 Hughes-Benzie RM, Allanson J, Hunter A, Cole T. The importance of differentiating Simpson-Golabi-Behmel and Beckwith-Wiedemann syndromes. F Med Genet 1992;29:228.
25 Weksberg R, Squire JA, Templeton DM. Glypicans: a growing trend. Nat Genet 1996;12:225-27.

26 Morison IM, Becroft DM, Taniguchi T, Woods CG, Reeve AE. Somatic overgrowth associated with overexpression of insulin-like growth factor II. Nat Med 1996;2:311-16.

27 Daling JR, Starzyk P, Olshan AF, et al. Birth weight and the incidence of childhood cancer. F Natl Cancer Inst 1984;72:1039-41.

28 Sotos JF, Dodge PR, Muirhead D, Crawford JD, Talbot NB. Cerebral gigantism in childhood. $N$ Engl f Med 1964;271:109-16.

29 Schlesinger B. Gigantism (acromegalic in nature). Proc R Soc Med 1931;24: 1352

30 Cole TRP, Dennis NR, Hughes HE. Weaver syndrome: seven new cases and a review of the literature. In: Donnai D, Winter RM eds. Congenital malformation syndromes. London: Chapman Hall, 1994:267-80.

31 Fitch N. The syndromes of Marshall and Weaver. 7 Med Genet 1980;17:174-8

32 Cole TRP, Hughes HE. Sotos syndrome: a study of the diagnostic criteria and natural history. $\mathcal{F}$ Med Genet 1994;31:20-32.

33 Jaeken J, Schueren-Lodeweyckx MVAN, Eeckels R. Cerebral gigantism syndrome: a report of four cases and review of the literature. Zeitschrift fur Kinderheilkunde 1972;112:332-46.

34 Finegan JK, Cole TRP, Kingwell E, Smith ML, Smith M, Sitarenioe G. Language and behaviour in children with Sotos syndrome. $\mathcal{F}$ Am Acad Child Adolesc Psychiatry 1994;33:1307-15.

35 Hoyme HE, Byers PH, Guttmacher AK. Marshall-Smith syndrome: further evidence of an osteochondroplasia in long-term survivors. Proceedings of the Greenwood Genetics Center 1993;12:70.

36 Fryer A, Smith C, Rosenbloom L, Cole TRP. Autosomal dominant inheritance of Weaver syndrome. $\mathcal{F}$ Med Genet 1997;34:418-19.

37 Smith M, Fullwood P, Qi Y, Palmer S, Upadhyaya M, Cole T. No evidence for uniparental disomy as a common cause of Sotos' syndrome. F Med Genet 1997;34:10-12.

38 Van Heyningen V. One gene-four syndromes. Nature 1994;367:319-20.

39 Mulvihill JJ. Craniofacial syndromes: no such thing as a single gene disease. Nat Genet 1995;9:101-3.

40 Dietz HC, Cutting GR, Pyeritz RE, et al. Marfan syndrome caused by a recurrent de novo missense mutation in the fibrillin gene. Nature 1991;352:337-9.

41 Putnam EA, Zhang H, Ramirez F, Milewicz D. Fibrillin-2 (FBN2) mutations result in the Marfan-like disorder, congenital contractural arachnodactyly. Nat Genet 1995;11:456-8.

42 Sood S, Eldahah ZA, Krause WL, McIntosh I, Dietz HC. Mutations in Fibrillin 1 and the marfanoid-craniosynostosis (Shprintzen-Goldberg) syndrome. Nat Genet 1996;12:209-11.

43 Stephan MJ, Hall BD, Smith DW, Cohen MM. Macrocephaly in association with unusual cutaneous angiomatosis. Pediatrics 1975;87:353-9.

44 Stevenson RE, Schroer RJ,Skinner C, Fender D, Simensen RJ. Autism and macrocephaly. Lancet 1997;349:1744-5.

45 Schwindinger WF, Francomano CA, Levine MA. Identification of a mutation in the gene encoding $\alpha$ subunit of the stimulatory $\mathrm{G}$ protein of adenyl cyclase in McCune-Albright syndrome. Proc Natl Acad Sci USA 1992;89:5152-6.

\section{Diagnosing Friedreich's ataxia}

The condition that now bears his name was first described by Nicolaus Friedreich in a series of papers between 1863 and 1877 . He noted the onset at around puberty of ataxia and dysarthria; sensory loss and weakness developed later. The skeletal deformities of pes cavus and scoliosis were also reported. Over the following generations there was a tendency to lump the inherited ataxias together, and the essential features of Friedreich's ataxia became diluted. Clinical studies in the 1970 s and $1980 \mathrm{~s}^{12}$ and subsequent genetic studies have helped clarify these features, and Friedreich's ataxia is now known to be the commonest of the inherited ataxias, accounting for at least $50 \%$ in most large series and affecting approximately one in 50000 individuals. ${ }^{3}$ Although at present it is an incurable and progressive disease, recent identification of the affected gene has not only provided a highly sensitive and specific diagnostic test, but has also given useful insight into the cellular pathology which may lead to the development of effective treatment.

\section{Clinical diagnosis}

Despite the relatively homogeneous clinical picture of an early onset of progressive ataxia involving the trunk and the limbs, it was necessary to formulate strict clinical criteria in order to perform genetic linkage analyses, and two notable studies, ${ }^{12}$ provided these. Harding's criteria (table 1) were widely adopted and are still useful today, although of course we are now able to reinterpret "atypical" cases in the light of available genetic data.

In addition to ataxia, there are several variable features, including pyramidal tract involvement. Initially this may be mild, with only extensor plantar responses, but after five or more years a pyramidal type of weakness in the legs invariably occurs and this can eventually lead to paralysis. The association of extensor plantar responses, absence of ankle reflexes, and a progressive course provide the core features.

Skeletal abnormalities are also commonly found. These include scoliosis (85\%), and foot deformities; although pes cavus is the best known of these, pes planus and equinovarus are also often found. Amyotrophy of the lower leg and rarely of the hands may also be found. When all these features are present in a case of early onset (before 20 years of age) autosomal recessive ataxia, genetic analysis will prove that Friedreich's ataxia is the correct diagnosis in the vast majority. ${ }^{4}$ Additional clinical support for a suspected diagnosis includes optic atrophy, which occurs in $25 \%$ of cases; however, it is rare for there to be major visual impairment in Friedreich's ataxia (less than $5 \%$ ). ${ }^{2}$ Deafness is found in less than $10 \%$ of cases. 
The most important non-neurological feature of Friedreich's ataxia is cardiomyopathy. The exact proportion of patients with cardiomyopathy is still debated. However, in a study where hearts were examined in detail, over $90 \%$ were found to have abnormalities, though the clinical significance of some of the lesser changes is unclear. ${ }^{5}$ About $65 \%$ of patients have an abnormal electrocardiogram (ECG), with widespread $\mathrm{T}$ wave inversion in the inferolateral chest leads. The most frequent echocardiographic abnormality is concentric ventricular hypertrophy. ${ }^{6} \mathrm{Al}-$ though heart failure is a late event, referral to a cardiologist may be necessary as arrhythmias are an important cause of premature death. Review of the patient should therefore always include an ECG. It should also include an estimation of blood sugar, since diabetes is seen in approximately $10 \%$ of cases.

Before identification of the gene, additional investigations were done to screen for the associations listed above and to rule out other diseases with a similar presentation. Nerve conduction studies reveal a predominantly sensory neuronopathy with absent sensory action potentials. This differentiates Friedreich's from the Roussy-Levy variant of hereditary motor sensory neuropathy type 1 , which was at one time thought to be a "forme-fruste" of Friedreich's ataxia as it produces a sensory ataxia with absent tendon reflexes. The neurophysiological findings in this condition are those of a severe demyelinating process rather than an axonopathy.

It was noted in the early 1980 s that patients with vitamin E malabsorption associated with various disorders including abetalipoproteinaemia, chronic liver disease, and cystic fibrosis $^{7-12}$ could develop a spinocerebellar syndrome which resembled Friedreich's ataxia but could be distinguished by those additional features. In 1985 Harding et al described a patient in whom vitamin $\mathrm{E}$ deficiency was seen in the absence of malabsorption or other identified problem. ${ }^{13}$ Although this disorder has undergone various name changes, including several acronyms, most people have now settled for AVED (ataxia with isolated vitamin $\mathrm{E}$ deficiency). The gene responsible for this illness was linked to $8 \mathrm{q}^{14}$ and identified by Ouahchi et al. ${ }^{15}$ The gene encodes a protein called $\alpha$ tocopherol transporter protein, and abnormalities which ensue from mutations of this gene result in impaired incorporation of vitamin $\mathrm{E}$ into very low density lipoprotein. Therefore, although vitamin $\mathrm{E}$ is absorbed adequately, it is soon lost from the system as the circulating reservoir is dysfunctional. Although clinically there are similarities with Friedreich's ataxia, the neuronopathy is more central and therefore conduction studies are often normal. The clinical clue to the presence of this disease is a characteristic titubation which is rarely seen in classical Friedreich's ataxia. However, despite the rarity of this illness, supplementation with vitamin $\mathrm{E}$ can result in

Table 1 Strict diagnostic criteria (after Harding, 1981²)

\begin{tabular}{ll}
\hline Essential & Age of onset before 25 years \\
& Progressive ataxia of gait and limbs \\
& Absent knee and ankle jerks \\
& Axonal picture on neurophysiology \\
& Dysarthria (if after five years from onset) \\
Additional (present in over 66\%) & Scoliosis \\
& Pyramidal weakness in lower limbs \\
& Absent reflexes in arms \\
& Large fibre sensory loss on examination \\
& Abnormal ECG \\
& Nystagmus \\
Others (less than 50\%) & Optic atrophy \\
& Deafness \\
& Distal amyotrophy \\
& Pes cavus \\
& Diabetes \\
\hline
\end{tabular}

either modest improvement of the clinical syndrome, or at least in cessation of its progression, and therefore it is always worthwhile measuring vitamin $\mathrm{E}$ in such patients. Since absorption is normal, a direct inquiry should be made about the use of supplementary vitamins - it is possible to be misled by a normal vitamin $\mathrm{E}$ level if vitamin $\mathrm{E}$ supplements are being taken.

If the spinocerebellar syndrome is complicated by other neurological problems, for example dementia, then other illnesses should be considered, including hexoseaminidase A deficiency, abetalipoproteinaemia, adrenoleucodystrophy, and related conditions.

The natural history of this disease unfortunately remains one of relentless progression, with dysarthria and pyramidal weakness presenting within a few years of onset, followed by jerky eye movements giving way to nystagmus. The patient usually becomes wheelchair bound within 10 to 15 years of onset. ${ }^{2}$ It is worth noting that patients may present to cardiologists with cardiomyopathy as the sole initial feature. We have recently seen two cases who presented with a choreiform movement disorder with no signs of ataxia. The clue that Friedreich's ataxia was the underlying condition was given by the absence of reflexes in both, scoliosis in one, and cardiomyopathy in the other. ${ }^{16}$

\section{Genetic diagnosis}

The gene for Friedreich's ataxia was mapped to chromosome 9 q13 in 1988 by Chamberlain and colleagues. ${ }^{17}$ There then followed a competitive hunt for the gene and a refinement of the genetic locus. This allowed a re-evaluation of the strict clinical criteria described above and it became apparent that the onset of Friedreich's ataxia could be seen after the age of 20 years, and retention of the tendon reflexes did not completely exclude it. It was also shown that the milder variant of the disease described in the Acadian population was mapped to the same locus. Following international collaboration, an anonymous transcript called X25 in which three point mutations were found was identified in $1996 .^{18}$ Further work showed that the predominant mutation was a trinucleotide repeat (GAA) in intron 1 of this gene. Expansion of both alleles was found in over 70 patients. In three patients point mutations were found on one allele and an expansion on the other. This is clear evidence that X25 is directly involved in Friedreich's ataxia, although there is still some debate as to the exact construction of the gene itself. ${ }^{19}$ Moreover, initial mRNA studies have reported a decrease in frataxin protein. Interestingly, the tissue specific distribution seen in this disease-including expression in the pancreas, the heart, and the dorsal spinal cord-mirrors that of the pathology of the disease.

This was the first autosomal recessive condition found to be due to a dynamic repeat, and it permitted the introduction of a specific and sensitive diagnostic test as it is a relatively simple matter to measure the repeat size. On normal chromosomes the number of GAA repeats varies from seven to 22 units, whereas on disease chromosomes the range varies from around 100 to 2000 repeats. This is in sharp contrast to the modest exonic repeat expansions seen in the dominant genetic ataxias (SCA 1,2, and 3), where an expansion of somewhere over 40 repeats is sufficient to cause a degenerative ataxia.

The polymerase chain reaction (PCR) with nucleotide primers spanning the repeated region is used to amplify the DNA in intron 1, and the products are then fractionated on an agarose or polyacrylamide gel (fig 1). The rarity of point mutations means that it is extremely unlikely that a case of Friedreich's will have two point mutations, and therefore a normal sized repeat length on both chromosomes is strongly against a diagnosis of Friedreich's ataxia. To put this into some sort of perspective, there is approximately a 


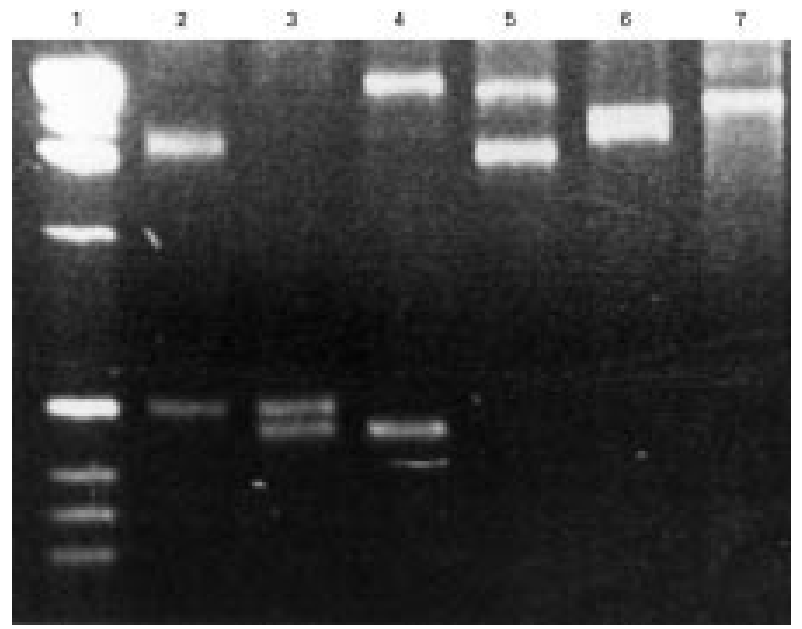

Figure 1 Agarose gel of long range PCR products of the repeated region of intron 1. Lane 1 shows the marker. Lanes 2 and 4 represent carriers of the expansion. Lane 3 is a normal "heterozygote" with two normal sized (but polymorphic) repeat alleles. Lane 5 shows an affected patient with two expanded alleles (approximate 900 and 1100 repeats respectively).

Lane 6 is a second affected patient with two more closely sized alleles

( 1000 +/- repeats). Lane 7 is a "homozygote" positive control.

one in 2500 chance that a patient with typical Friedreich's ataxia will have a double point mutation. However, the phenotype of atypical cases is still unresolved.

The exact mechanism of action of this repeat in intron 1 is not known, but it is likely that this huge expansion disrupts normal splicesome binding and therefore exon 1 is not spliced correctly to exon 2 . This is reflected in a reduction in mRNA and protein levels.

There has been progress in our understanding of the protein. ${ }^{20} \mathrm{~A}$ very recent report ${ }^{21}$ has investigated a yeast analogue of the protein and shown it to be a mitochondrial iron transporter. There is preliminary evidence in human studies that frataxin is also mitochondrially placed (M Pandolfo, personal communication). If this is indeed the function of frataxin in humans, the corollary of this is that iron will build up inside the mitochondria with relative diminution in the cytosol. The free iron may cause a number of problems but most interest concerns free radical regulation and oxidative phosphorylation. Clinically this fits-a syndrome of ataxia and neuropathy, in association with diabetes, cardiomyopathy, deafness and optic atrophy, has all the hallmarks of a mitochondrial disease, so perhaps Friedreich's ataxia will turn out to be the commonest mitochondrial disease of all!

\section{Genotype-phenotype correlations}

The identification of a diagnostic test has allowed the clinical phenotype to be re-evaluated. It is now confirmed that retained tendon reflexes are present in a small proportion of patients with Friedreich's ataxia. Although most patients present below the age of 25, onset can be later than this and the oldest reported case was 51 years. ${ }^{22}$ Studies of large numbers of patients ${ }^{4223}$ are in broad agreement that the length of repeat size is a determinant of the age of onset and therefore to some degree influences the severity of the disease, in that cases with early onset tend to progress more rapidly. However, this correlation applies to populations of patients and is not useful in guiding an individual patient or family. The presence of cardiomyopathy is also linked to the length of the repeat, but further studies are needed to disentangle the exact relation between the two. ${ }^{23}$

We have also identified three families in whom inheritance initially appeared to be dominant, as in all three cases the parent had an ataxic syndrome. In one of these families, pseudodominance has been proved by identifica-

\section{Key messages}

- Friedreich's ataxia is the commonest inherited ataxia (1:50 000)

- Over $97 \%$ will have a homozygous GAA unstable repeat in intron 1 of the frataxin gene on chromosome $9 \mathrm{q}$; a direct test is now available

- There is a correlation between repeat length and age at onset

- The frataxin protein may be an iron transporter within the mitochondria

tion of two abnormal alleles in the parental generation as well as two in the affected offspring, that is, it was a case of a patient marrying a carrier. In the other two families, the children have both clinical and genetic Friedreich's ataxia. However, the fathers have a more complicated ataxia and a later onset. They are heterozygotes for the expansion, and the possibility arises that either they both have point mutations which are modifying the phenotype, or they have ataxia from some other cause.

\section{Summary}

Clinical diagnosis is still of the utmost importance and following our review of cases diagnosed using the strict criteria, $100 \%$ were homozygous for the expansion. ${ }^{4}$ However, now that there is a relatively simple direct genetic test, the diagnosis can be considered in more unusual cases. Genetic testing has been shown to be of value in establishing the correct diagnosis and in directing the appropriate screening tests, including cardiological assessment and blood sugar estimation.

Perhaps the most interesting development following identification of the gene is the rapid progress in our understanding of the protein. If, as seems likely, it turns out to be a mitochondrial protein involved in iron transport, it gives cause for hope of effective treatment.

\section{NICHOLAS W WOOD}

Department of Clinical Neurology,

Institute of Neurology,

National Hospital for Neurology and Neurosurgery,

Queen Square, London WC1N 3BG

1 Geoffroy G, Barbeau A, Breton G, et al. Clinical description and roentgenologic evaluation of patients with Friedreich's ataxia. Can $\mathcal{F}$ Neurol Sci 1976;3:279-86.

2 Harding AE. Friedreich's ataxia: a clinical and genetic study of 90 families with an analysis of early diagnostic criteria and intrafamilial clustering of clinical features. Brain 1981;104:589-620.

3 Harding AE, Zilkha KJ. "Pseudo-dominant" inheritance in Friedreich's ataxia. $\mathcal{F}$ Med Genet 1981;18:285-7.

4 Lamont P, Sweeney M, Wood N. Identification and sizing of the GAA trinucleotide repeat expansion of Friedreich's ataxia in 56 patients. Brain 1997; 120:673-80.

5 Harding AE. The inherited ataxias. Adv Neurol 1988;48:37-46.

6 Pentland B, Fox KA. The heart in Friedreich's ataxia. 7 Neurol Neurosurg Psychiatry 1983;46:1138-42.

7 Elias E, Muller DP, Scott J. Association of spinocerebellar disorders with cystic fibrosis or chronic childhood cholestasis and very low serum vitamin E Lancet 1981;ii:1319-21.

8 Harding AE, Muller DP, Thomas PK, et al. Spinocerebellar degeneration secondary to chronic intestinal malabsorption: a vitamin E deficiency syndrome. Ann Neurol 1982;12:419-24.

9 Muller DP, Lloyd JK, Wolff OH. Vitamin E and neurological function. Lancet 1983;i:225-8.

10 Muller DP, Lloyd JK, Bird AC. Long-term management of abetalipoproteinaemia. Arch Dis Child 1977;52:209-14.

11 Rosenblum JL, Keating JP, Prensky AL, et al. A progressive neurologic syndrome in children with chronic liver disease. N Engl f Med 1981;304:5038 .

12 Sitrin MD, Lieberman F, Jensen WE, et al. Vitamin E deficiency and neurologic disease in adults with cystic fibrosis. Ann Intern Med 1987;107:51-4.

13 Harding AE, Matthews S, Jones S, et al. Spinocerebellar degeneration associated with a selective defect of vitamin E absorption. N Engl f Med 1985; 313:32-5.

14 Ben Hamida C, Doerflinger N, Belal S, et al. Localisation of Friedreich's ataxia phenotype with selective vitamin $\mathrm{E}$ deficiency to chromosome $8 \mathrm{q}$ by ataxia phenotype with selective vitamin E deficiency to

15 Ouahchi K, Arita M, Kayden $\mathrm{H}$, et al. Ataxia with isolated vitamin $\mathrm{E}$ deficiency is caused by mutations in the alpha-tocopherol transfer protein. Nat Genet 1995;9:141-5. 
16 Hanna MG, Davis MB, Sweeney MG, et al. Generalised chorea in two patients harbouring the Friedreich's ataxia trinucleotide repeat expansion. patients harbouring the Fried
Movement Disorders (in press).

17 Chamberlain S, Shaw J, Rowland A, et al. Mapping of mutation causing Friedreich's ataxia to human chromosome 9. Nature 1988;334:248-50

18 Campuzano V, Montermini L, Molto MD, et al. Friedreich's ataxia: autosomal recessive disease caused by an intronic GAA triplet repeat expansion. Science 1996;271:1423-7.

19 Carvajal JJ, Pook MA, dos Santos M, et al. The Friedreich's ataxia gene encodes a novel phosphatidylinositol-4-phosphate 5-kinase. Nat Genet 1996;14:157-62.
20 Gibson TJ, Koonin EV, Musco G, et al. Friedreich's ataxia protein: phylogenetic evidence for mitochondrial dysfunction. Trends Neurosci 1996;19:465-

21 Babcock M, de Silva D, Oaks R, et al. Regulation of mitochondrial iron accumulation by Yfh1p, a putative homolog of frataxin. Science 1997;276: 1709-12.

22 Durr A, Cossee M, Agid Y, et al. Clinical and genetic abnormalities in patients with Friedreich's ataxia. $N$ Engl $\mathcal{F}$ Med 1996;335:1169-75.

23 Filla A, De Michele G, Cavalcanti F, et al. The relationship between trinucleotide (GAA) repeat length and clinical features in Friedreich ataxia. $\mathrm{Am}$ f Hum Genet 1996;59:554-60.

\section{Treatment of hyperthyroidism in young people}

Graves' disease is rare in childhood but occurs with increasing frequency into adolescence and young adult life. There is a strong familial predisposition but the precipitating cause is not known. Stimulation of the thyroid stimulating hormone (TSH) receptor by autoantibodies causes excessive thyroid hormone production and secretion, and diffuse enlargement of the thyroid. Other systems may be involved, notably the eyes with proptosis. In children the early symptoms of hyperthyroidism are non-specific and may be of gradual onset; unless there is an obvious goitre, a psychological or behavioural disorder is often suspected. Once considered, the diagnosis is readily confirmed biochemically by raised concentrations of circulating thyroid hormones and suppression of TSH.

The aim of treatment is to restore and maintain permanent euthyroidism as safely, quickly, and conveniently as possible. Especially in young people, there is no consensus on how this is best achieved and in this annotation we shall consider the options.

\section{Initial management}

The symptoms of hyperthyroidism may be distressing and can be relieved promptly to a great extent by blocking the peripheral effects of the excess thyroid hormones. A $\beta$ blocking agent such as propranolol, $1 \mathrm{mg} / \mathrm{kg} /$ day in divided doses, is effective and useful to tide the patient over until the disease is controlled.

An antithyroid drug can be started at the same time. The thionamide drugs block the synthesis of thyroid hormones and also have ill understood immunosuppressive effects in Graves' disease. ${ }^{1}$ Carbimazole is more widely used in Europe and propylthiouracil in the United States; although their actions and side effect profiles are slightly different, in practice they are interchangeable. Carbimazole 0.5 to 1.0 $\mathrm{mg} / \mathrm{kg} /$ day or propylthiouracil 5 to $10 \mathrm{mg} / \mathrm{kg} /$ day in divided doses brings the hyperthyroidism of Graves' disease under control in four to eight weeks.

If there is urgent need to cure the disease as soon as possible, it is then safe to proceed to thyroidectomy but most clinicians favour a trial of medical treatment in the hope that a long term remission will occur. This entails treatment with an antithyroid drug for 18 months to two years under regular supervision. When the circulating thyroid hormones are restored to the normal range, treatment can be reduced to a single daily dose and titrated against regular thyroid function tests to maintain euthyroidism. A more convenient approach is to continue the antithyroid drug unchanged and add thyroxine $100 \mu \mathrm{g} / \mathrm{m}^{2} /$ day in a "block and replace" regimen. ${ }^{2}$ Although there is continued exposure to the antithyroid drug in full dosage, less monitoring is needed and euthyroidism is more reliably maintained.

As with any long term treatment, many patients and their families find it remarkably difficult to remember to take the drugs regularly. Some $2-5 \%$ of patients develop a rash or other minor side effects with an antithyroid drug (usually nausea, headache, or arthralgia). If mild, the symptoms generally prove transient but if they persist the patient can be changed to the other major agent, as cross sensitivity is unusual. Serious side effects are rare, especially in young patients, but include neutropenia, agranulocytosis (which is nearly always reversible), and hepatotoxicity. ${ }^{34}$ If such effects occur they usually do so in the first few months of treatment. They cannot be predicted by frequent monitoring, so patients and parents must be warned to report promptly any episode of significant fever, sore throat, or other symptoms. It is our practice to request a blood count whenever checking on thyroid function but not to order tests otherwise.

At the end of the course of medical treatment the drugs are withdrawn and the child is observed for recurrent hyperthyroidism. Relapse is more likely in children than in adults, and in those with a low body mass index and a large goitre at presentation. ${ }^{56}$ The remission rate of children in the USA is reported to be $25 \%$ after each of repeated two year courses of medical treatment, ${ }^{7}$ with remission rates around $50-65 \%$ reported in adult studies. ${ }^{58}$ Of the wide variety of biochemical markers and dynamic tests that have been investigated in the hope of finding a method of predicting relapse, none has proved reliable. Hashizume and colleagues ${ }^{9}$ reported that giving thyroxine during and after treatment with antithyroid drugs greatly improved the remission rate, perhaps by reducing antigen presentation, but recent studies have not confirmed their findings. ${ }^{10} 11$ Relapse generally occurs within the first few months after treatment is withdrawn but can be long delayed. Patients in remission from Graves' disease are also at increased risk of becoming hypothyroid in the future, so a case can be made for continued infrequent checks on thyroid function.

If relapse occurs, there are three options: (1) to resume antithyroid drug treatment; (2) to proceed to thyroidectomy; (3) to treat the child with radioiodine. Here there is a transatlantic divide in approach. In Europe subtotal or total thyroidectomy has in general been the only option offered for definitive treatment. ${ }^{2}$ Some American units continue to report excellent surgical results ${ }^{12}$ but in many centres $^{13-15}$ radioiodine treatment is preferred in all age groups.

\section{Further medical treatment}

If medical treatment was well tolerated and regular supervision with thyroid function testing did not prove a burden, some patients and their families will prefer to resume antithyroid drug treatment. This could be for a further full course with the hope of remission at the end-which may be expected in up to $25 \%$ of those who have relapsed after the first course of treatment-or for a shorter time, with definitive treatment planned at a convenient moment. 


\section{Thyroidectomy}

Surgery provides one definitive therapeutic option. In the past, partial thyroidectomy was favoured with the hope of leaving sufficient thyroid tissue for the child to remain euthyroid. Too conservative an operation resulted in a high rate of recurrent hyperthyroidism and too radical a thyroidectomy in hypothyroidism; either of these problems could occur unpredictably many years later. ${ }^{16-18}$ Most surgeons now aim to render the child hypothyroid at the first operation by removing essentially all the gland. As soon as hypothyroidism is confirmed, thyroxine replacement can be started. Although compliance with replacement treatment does remain a concern, thyroxine dose adjustment through the years of growth and development is straightforward and no further changes are necessary once the patient is fully grown. Many areas in the United Kingdom now keep thyroid registers, and patients can be followed up by their general practitioners without the need for continuing hospital review.

A short hospital stay is needed and potential problems include the discomfort of the operation, the scar (which may form keloid), the small but appreciable risk of general anaesthetic and surgical complications, the specific risks of damage to the recurrent laryngeal nerves, and transient or permanent hypoparathyroidism. All these risks are reduced in the hands of expert thyroid surgeons, but such expertise is rare now that hyperthyroidism in adults is generally treated with radioiodine.

\section{Radioiodine}

This elegant form of treatment was first used 50 years ago and it has earned a remarkable safety record. ${ }^{19}$ Radioiodine can be given with the aim of leaving the patient euthyroid, or in a higher dose with the specific intention of ablating the gland and accepting permanent hypothyroidism. Adjustment of the dose in relation to the size and uptake of the gland may result in the temporary restoration of euthyroidism but eventual progression to hypothyroidism is likely at some stage. Since a primary objective of definitive treatment is to relieve the patient of the need for long term monitoring, ${ }^{17}{ }^{20}$ many centres have now adopted the policy of ablating the thyroid and accepting the need for thyroxine replacement ${ }^{21}$; this is particularly appropriate in children.

There has been concern that radioiodine treatment may aggravate Graves' ophthalmopathy, and steroid cover has been recommended to prevent this complication. ${ }^{22}{ }^{23}$ In our own experience and that of others this effect has not proved a problem; eye disease need not be considered a contraindication to radioiodine treatment. ${ }^{23}$

In the past in many centres the use of radioiodine was restricted to patients beyond their reproductive age. With increasing confidence in its safety it is now used throughout adult life but still often denied to children and adolescents because of lingering concerns about the possibility of long term adverse effects. These concerns are entirely appropriate but after 50 years use of radioiodine, there is no evidence that they are justified.

External irradiation is well known to cause thyroid cancer $^{24}$ and carcinogenesis may also result from exposure to low doses of ${ }^{131} \mathrm{I}$, as seen after the Chernobyl accident in the former Soviet Union. ${ }^{25}{ }^{26}$ Fortunately the risk of future thyroid cancer can be removed by ablating the gland and this provides a strong additional argument in favour of using this approach when treating young patients. ${ }^{27} 28$ There is no evidence of an increase in the incidence of leukaemia, ${ }^{29}$ or of reduced fertility or germ cell damage ${ }^{13} 30$ after therapeutic radioiodine. In a large group of patients, mainly adults, who received a mean dose of $506 \mathrm{Mbq}$ and were followed for a mean of 15 years there was no overall increase in cancer, ${ }^{28}$ although a small excess of stomach cancer was observed in this one study only.

Although it is conceivable that greatly delayed adverse effects of radioiodine in young people might yet emerge, many clinicians now consider radioiodine a treatment of first choice in young patients with Graves' disease who relapse after medical treatment. Radioiodine has become an even more acceptable option since it has become apparent that lifelong thyroxine replacement is also needed after surgery.

In the past 10 years we have treated eight young patients with radioiodine. They were given an initial dose of 300 Mbq of ${ }^{131} \mathrm{I}$ with the intention of ablating the gland. Medical treatment was resumed for six months and then withdrawn. Four patients became hypothyroid after a single dose of radioiodine, but four needed a second dose. All became hypothyroid within two years. No adverse effects were observed, in particular there was no deterioration of the eye disease in any patient.

Some precautions are necessary after radioiodine treatment. Close and prolonged physical contact with others should be avoided for three days and we recommend that children stay away from school for two weeks. ${ }^{31}$ For older girls the importance of avoiding pregnancy for least six months should be stressed. ${ }^{32}$

\section{Conclusions}

Once diagnosed, Graves' disease can readily be controlled, but there is no ideal form of treatment for young people. Detailed discussion of the advantages, disadvantages, and risks of each of the different forms of treatment is important so that a therapeutic plan can take into account the needs and wishes of the patient and family.

Unless there are compelling reasons to seek a rapid cure, an initial trial of medical treatment using a "block and replace" regimen for 18 to 24 months is recommended. For the majority who relapse when antithyroid drug treatment is withdrawn, medical treatment can be resumed but definitive treatment should be considered. If excellent surgical services are available, total thyroidectomy with subsequent thyroxine replacement provides a definitive solution with low risk. Treatment with radioiodine offers a simple alternative without short term risks and with an excellent long term safety record which justifies its use in young patients. Given the choice, many will opt for this form of treatment and our experience suggests that a dose of $400 \mathrm{mbq}$ of ${ }^{131} \mathrm{I}$ will reduce the number of patients requiring a second dose. We recommend an approach in which the gland is ablated and the need for thyroxine replacement is accepted.

T D CHEETHAM I A HUGHES N D BARNES

Department of Paediatrics,

Addenbrooke's Hospital,

Cambridge

Department of Nuclear Medicine,

Addenbrooke's Hospital,

Cambridge

Correspondence to: Dr Tim Cheetham, Children's Endocrine and Metabolic Service, Royal Victoria Infirmary, Queen Victoria Road, Newcastle upon Tyne NE1 4LP.

Weetman AP. How antithyroid drugs work in Graves' disease. Clin Endocrinol (Oxf) 1992;37:317-18.

2 Perrild H, Gruters-Kieslich A, Feldt-Rasmussen U, et al. Diagnosis and treatment of thyrotoxicosis in childhood. A European questionnaire study. Eur 7 Endocrinol 1994;131:467-73.

3 Cooper DS, Goldminz D, Levin AA, et al. Agranulocyosis associated with antithyroid drugs: effects of patient age and drug dose. Ann Intern Med antithyroid drug

4 Williams KV, Nayak S, Becker D, et al. Fifty years of experience with propylthiouracil-associated toxicity: what have we learned? $\mathcal{f}$ Clin Endocrinol Metab 1997;82:1727-33. 
5 Winsa B, Dahlberg PA, Jansson R, et al. Factors influencing the outcome of thyrostatic drug therapy in Graves' disease. Acta Endocrinol 1990;122:722thyr

6 Glaser NS, Styne DM. Predictors of early remission of hyperthyroidism in children. F Clin Endocrinol Metab 1997;82:1710-26.

7 Lippe BM, Landaw EM, Kaplan SA. Hyperthyroidism in children treated with long term medical therapy: twenty-five percent remission every two years. F Clin Endocrinol Metab 1987:64:1241-5.

8 Weetman AP, Pickerill AP, Watson P, et al. Treatment of Graves' disease with the block-replace regimen of antithyroid drugs: the effect of treatment duration and immunogenetic susceptibility on relapse. $Q \mathcal{f}$ Med 1994;87:337-41.

9 Hashizume K, Ichikawa K, Sakurai A, et al. Administration of thyroxine in treated Graves' disease. Effects on the levels on antibodies to thyroidstimulating hormone receptors and on the risk of recurrence of hyperthyroidism. N Engl f Med 1991;324:947-53.

10 Tamai H, Hayaki I, Kawai K, et al. Lack of effect of thyroxine administration on elevated thyroid stimulating hormone receptor antibody levels in treated on elevated thyroid stimulating hormone receptor antibody levels in
Graves' disease patients. F Clin Endocrinol Metab 1995;80:1481-4.

11 McIver B, Rae P, Beckett G, et al. Lack of effect of thyroxine in patients with Graves' hyperthyroidism who are treated with an antithyroid drug. $N$ Engl Graves' hyperthyroidism

12 Soreide JA, van Heerden JA, Lo CY, et al. Surgical treatment of Graves' disease in patients younger than 18 years. World F Surg 1996;20:794-9.

13 Safa AM, Schumacher P, Rodriguez-Antunez A. Long-term follow-up results in children and adolescents treated with radioactive iodine $\left({ }^{131} \mathrm{I}\right)$ for hyperthyroidism. N Engl f Med 1975;292:167-71

14 Freitas JE, Swanson DP, Gross MD, et al. Iodine-131: optimal therapy for hyperthyroidism in children and adolescents? F Nucl Med 1979;20:847-50.

15 Hamburger JI. Management of hyperthyroidism in children and adolescents. F Clin Endocrinol Metab 1985:60:1019-24.

16 Rudberg C, Johansson H, Åkerström G, et al. Graves' disease in children and adolescents. Late results of surgical treatment. Eur F Endocrinol 1996;134: $710-15$.

17 Franklyn JA, Daykin J, Droic Z, et al. Long-term follow-up of treatment of thyrotoxicosis by three different methods. Clin Endocrinol 1991;34: $71-6$.

18 Miccoli P, Vitti P, Rago T, et al. Surgical treatment of Graves' disease: subtotal or total thyroidectomy? Surgery 1996;120:1020-5.
19 Lazarus JH. Guidelines for the use of radioiodine in the management of hyperthyroidism: a summary. F R Coll Physicians Lond 1995;29:464-9.

20 Hardisty CA, Jones SJ, Hedley AJ, et al. Clinical outcome and costs of care in radioiodine treatment of hyperthyroidism. $\mathcal{F}$ R Coll Physicians Lond 1990; 24:36-42.

21 Kendall-Taylor P, Keir MJ, Ross WM. Ablative radioiodine therapy for hyperthyroidism: long term follow up. BMF 1984:289:361-3.

22 Tallstedt L, Lundell G, Torring $\mathrm{O}$, et al. Occurrence of ophthalmopathy after treatment for Graves' hyperthyroidism. N Engl F Med 1992;326:1733-8.

23 DeGroot LJ, Gorman CA, Pinchera A, et al. Therapeutic controversies. Radiation and Graves' ophthalmopathy. F Clin Endocrinol Metab 1995;80: 339-49.

24 Barnes ND. Effects of external irradiation on the thyroid gland in childhood. Horm Res 1988;30:84-9.

25 Nikiforov Y, Gnepp DR, Fagin JA. Thyroid lesions in children and adolescents after the Chernobyl disaster: implications for the study of radiation tumorigenesis. f Clin Endocrinol Metab 1996;81:9-14.

26 Williams D. Thyroid cancer and the Chernobyl accident [editorial]. $\mathcal{F}$ Clin Endocrinol Metab 1996;81:6-8.

27 Dobyns BM, Sheline GE, Workman JB, et al. Malignant and benign neoplasms of the thyroid in patients treated for hyperthyroidism: a report of the cooperative thyrotoxicosis therapy follow-up study. 7 Clin Endocrinol Metab 1974;38:976-8.

28 Holm L-E, Hall P, Wiklund K, et al. Cancer risk after iodine-131 therapy for hyperthyroidism. F Natl Cancer Inst 1991;83:1072-7.

29 Hall P, Boice JD, Berg G, et al. Leukaemia incidence after iodine-131 exposure. Lancet 1992;340:1-4.

30 Sarker SD, Beierwaltes WH, Gill SP, et al. Subsequent fertility and birth histories of children treated with ${ }^{131} \mathrm{I}$ for thyroid cancer. 7 Nucl Med 1976;17: 460-4.

31 National Radiological Protection Board. Guidance notes for the protection of persons against ionising radiations arising from medical and dental use. London: Department of Health and Social Services, 1988:57-9.

32 Administration of Radioactive Substances Advisory Committee. Notes for guidance on the administration of radioactive substances to persons for purposes of diagnosis, treatment or research. London: Department of Health, 1993. 